\title{
Influence of Lactic Acid Bacteria Fermentation on Physicochemical Properties and Antioxidant Activity of Chickpea Yam Milk
}

\author{
Xue Zhang, ${ }^{1,2}$ Shuai Zhang, ${ }^{1}$ Bijun Xie, ${ }^{1}$ and Zhida Sun $\mathbb{D}^{1}$ \\ ${ }^{1}$ College of Food Science and Technology, Huazhong Agricultural University, Wuhan, Hubei 430070, China \\ ${ }^{2}$ College of Food Engineering, Henan University of Animal Husbandry and Economy, Zhengzhou, Henan 450011, China
}

Correspondence should be addressed to Zhida Sun; sunzhidawh@163.com

Received 28 February 2021; Revised 10 April 2021; Accepted 15 April 2021; Published 27 April 2021

Academic Editor: Shengbao Cai

Copyright (c) 2021 Xue Zhang et al. This is an open access article distributed under the Creative Commons Attribution License, which permits unrestricted use, distribution, and reproduction in any medium, provided the original work is properly cited.

\begin{abstract}
This study aimed to evaluate the influence of lactic acid bacteria fermentation on the physicochemical properties and antioxidant activity of chickpea yam milk. Four groups of chickpea milk were prepared through fermentation with lactic acid bacteria for quality and functionality improvement. Results indicate that the polysaccharide content of four samples declines during the fermentation process, and their infrared spectrums are similar with a slight difference in the transmittances of some characteristic bands. The sodium dodecyl sulfate-polyacrylamide gel electrophoresis (SDS-PAGE) profiles of four samples with $24 \mathrm{~h}$ fermentation showed a band disappearance in the range of $94.3 \mathrm{KDa}$ and generation of many small-molecule peptides, revealing the protein degradation during fermentation. The moderate enzymatic hydrolysis had no adverse effect on the texture and color of the samples. A substantial increase in DPPH, ABTS radical scavenging rates, and FRAP value was observed after $12 \mathrm{~h}$ fermentation, especially the CPBY sample. The present results indicate that lactic acid bacteria fermentation can be used to improve the physicochemical properties of samples and enhance their antioxidant activity.
\end{abstract}

\section{Introduction}

With increasing concern for health (lactose intolerance and animal milk allergies), environment protection, and sustainability, the interest and demand for plant-based milk are growing [1]. Plant-derived milk is made from legumes, cereals, or edible plant seeds $[2,3]$. Applying lactic acid bacteria fermentation to plant-based milk is a subtrend of innovative plant-derived products. This process provides a natural method to increase the safety, nutrition, and shelf life of plant-derived products. The biological activities of plantbased products can be improved by fermentation because microbial proteases promote protein degradation and generate bioactive peptides during fermentation. Researchers demonstrated that lactic acid bacteria possess the ability to hydrolyze proteins [4]. Studies have proven that the concentrations of bioactive components, such as small-size peptides and free amino acids, are improved by fermentation
[5]. Thus, the microbial modification of lactic acid bacteria fermented beans is an effective method to increase their antioxidant and/or other biological activities.

In recent years, relevant studies have been conducted on the process optimization and antioxidant properties of plant-based fermented milk. Traditional fermented soybean products have been increasingly recognized to have powerful antioxidant effects. Soymilk fermented with Lactobacillus paracasei KUMB B005 has a credible antioxidative potential [6]. The contents of antioxidant compounds in fermented soymilk are closely related to reducing power and antiradical ability. A previous study reported that the antioxidant capacity is highly correlated with proteolytic activity [7]. Glucosidase produced by lactobacilli in the fermentation process can hydrolyze soybean isoflavone from glycoside to aglycone, causing them to exhibit strong biological activity [8]. Fermented soymilk can enrich B group vitamins, promote gut health, and enrich anticancer effect [9]. 
Chickpea (Cicer arietinum L.) is the third most important pulse crop in production, next to dry beans and field peas [10]. Compared with other legumes, chickpea is a good source of protein and carbohydrates, accounting for approximately $80 \%$ of the total dry seed mass [11]. Chickpea is also rich in minerals, dietary fiber, and vitamins [12]. The demand for chickpea milk as a good substitute for soymilk is increasing due to its nonallergenic and nutritional value $[13,14]$. Yam, a famous food material, has a sweet taste and contains a variety of substances with antioxidant activity, which is good for the spleen. A previous study found that Chinese yam extract induces an improvement in digestive capability and affects the conversion of some intestinal flora to beneficial gut bacteria [15]. Therefore, adding yam to chickpea fermented milk may help to improve the flavor, function, and nutrition of chickpea fermented milk. Previous studies illustrated the effect of fermentation technology on the quality of chickpea milk $[14,16]$. However, whether the physicochemical properties and antioxidant activity of chickpea yam milk can be positively influenced by lactic acid bacteria fermentation remains unknown. Therefore, this study aimed to evaluate the influence of lactic acid bacteria fermentation on the physicochemical characteristics and antioxidant activity of chickpea yam milk before and after fermentation. The findings are expected to provide theoretical support for developing new products of yam and chickpea milk.

\section{Materials and Methods}

2.1. Raw Materials and Chemicals. Untoasted chickpeas (Desi), yam, and sugar were purchased from a local supermarket (Zhengzhou, China). Papain $\left(10^{4} \mathrm{U} / \mathrm{g}\right)$ was purchased from Nanning Pangbo Biological Engineering Co., Ltd. (Nanning, China). Cellulase was purchased from Ningxia Heshibi Biotechnology Co., Ltd. (Ningxia, China). Lacticaseibacillus rhamnosus CICC 20257 was purchased from the China Center of Industrial Culture Collection (Beijing, China). Chemicals required for the analysis including 2,2'-azinobis-3-ethylbenzthiazoline-6-sulphonate $\left(\mathrm{ABTS}^{+}\right)$and 1,1-diphenyl-2-picrylhydrazyl (DPPH) were purchased from Sigma Chemical Co. (St. Louis, USA). All other chemicals used were of analytical grade and obtained from Sinopharm Chemical Reagent Co., Ltd. (Shanghai, China).

2.2. Preparation of Fermented Chickpea Yam Milk. Chinese yam was pulverized into powder on a 200-mesh sieve and was mixed with deionized water (ratio $2: 7 \mathrm{w} / \mathrm{v}$ ). The yam milk was heated at $100^{\circ} \mathrm{C}$ for $2 \mathrm{~min}$ to inactivate the enzyme.

Fermented chickpea milk was prepared as follows: whole chickpeas were washed and soaked for $12 \mathrm{~h}$ in distilled water. A total of $200 \mathrm{~g}$ of swollen chickpeas was ground in $1.6 \mathrm{~L}$ water (ratio $1: 8 \mathrm{w} / \mathrm{v}$ ). The slurry was cooked at $85^{\circ} \mathrm{C}$ for $15 \mathrm{~min}$ and then filtered with double-layer gauze to separate insoluble residues. The filtrate was transferred into glass bottles and sterilized at $100^{\circ} \mathrm{C}$ for $15 \mathrm{~min}$. After being cooled to room temperature, chickpea milk was evenly divided into four groups. The first group consisted of chickpea milk and water at a ratio of $8: 3$ without adding enzyme and denoted as CP. The second group was made by mixing chickpea milk and water at a ratio of $8: 3$ with addition of $80 \mathrm{U}$ papain per chickpea protein gram and denoted as $\mathrm{CPB}$. This group was kept at $50^{\circ} \mathrm{C}$ for $30 \mathrm{~min}$ and then boiled to inactivate the enzyme. The third group was prepared by mixing chickpea milk and yam milk at a ratio of $8: 3$ without adding enzyme and marked as CPY. The fourth group was made by mixing chickpea milk and yam milk at a ratio of $8: 3$ with addition of $80 \mathrm{U}$ papain per chickpea protein gram and marked as $\mathrm{CPBY}$. This group was kept at $50^{\circ} \mathrm{C}$ for $30 \mathrm{~min}$ and then boiled to inactivate the enzyme. All samples were added with sucrose (previously sterilized by filtration) with a final concentration of $5 \%(\mathrm{v} / \mathrm{v})$ and then stored at $4^{\circ} \mathrm{C}$.

Lacticaseibacillus rhamnosus CICC 20257 was used as a starter for the production of fermented chickpea milk. The microorganism was propagated $(1 \%, v / v)$ twice in MRS broth [17] and incubated at $37^{\circ} \mathrm{C}$ for $24 \mathrm{~h}$ without stirring in microaerophilic condition.

Four hundred milliliters of each chickpea milk sample was inoculated with $2 \%(\mathrm{v} / \mathrm{v})$ (more than $\left.1 \times 10^{8} \mathrm{cfu} / \mathrm{mL}\right)$ of an active culture of Lacticaseibacillus rhamnosus CICC 20257, and the mixture was allowed to ferment at $37^{\circ} \mathrm{C}$ for $24 \mathrm{~h}$. The sample was aseptically collected at $0,3,6,9,12$, and $24 \mathrm{~h}$, immediately cooled on ice, and stored at $4^{\circ} \mathrm{C}$ until analysis.

\subsection{Measurements of Polysaccharides from Chickpea Samples before and after Fermentation}

2.3.1. Extraction of Polysaccharides. The extraction of polysaccharides was determined in accordance with the previous method [18] with some modifications. Samples $(20 \mathrm{~mL})$ of $0,3,6,9,12$, and $24 \mathrm{~h}$ were mixed with deionized water at a ratio of $1: 10$. The $\mathrm{pH}$ of the mixture was adjusted to 5.0 by adding sodium acetate-acetic acid buffer, and then $1 \%$ cellulase was added. Subsequently, polysaccharide was extracted by ultrasonic method $(300 \mathrm{~W})$ at $50^{\circ} \mathrm{C}$ for $30 \mathrm{~min}$. The slurry was filtered through vacuum filtration after the extraction. The filtrate was stirred with medium-speed magnetic for $10 \mathrm{~min}$ and then centrifuged at $6,000 \mathrm{~g}$ for $10 \mathrm{~min}$ to remove the protein. The supernatant was collected and was mixed with $95 \%$ ethanol at a ratio of $1: 3$ for $12 \mathrm{~h}$ at $4^{\circ} \mathrm{C}$ until white precipitation appeared. The residue was washed with $85 \%$ ethanol twice and dried at $60^{\circ} \mathrm{C}$ for $2 \mathrm{~h}$ after centrifugation. The content of polysaccharides was determined by the phenol-sulfuric acid method.

2.3.2. FTIR Spectra Interpretation. Dry polysaccharide (approximately $2 \mathrm{mg} /$ sample) from fermented samples of 0 , 12 , and $24 \mathrm{~h}$ was mixed with $100 \mathrm{mg}$ of $\mathrm{KBr}$. The spectrum was collected with a Fourier transform infrared spectroscopy (FTIR) spectrometer (iS ${ }^{\text {TM }} 10$ FTIR Persee, Beijing, China) at $4 \mathrm{~cm}^{-1}$ resolution for 32 scans in the range of $4,000-400 \mathrm{~cm}^{-1}$. 
2.4. Measurements of SDS-PAGE. In accordance with the modified method [19], sodium dodecyl sulfate-polyacrylamide gel electrophoresis (SDS-PAGE) was conducted to characterize the changes in protein during the fermentation process. The samples $(20 \mu \mathrm{L} /$ sample $)$ collected at 0 and $24 \mathrm{~h}$ were mixed with loading buffer $(20 \mu \mathrm{L})$ at $1: 1$ ratio. The mixture was boiled at $100^{\circ} \mathrm{C}$ for $5 \mathrm{~min}$ to induce protein denaturation, kept in an ice bath for $3 \mathrm{~min}$, and centrifuged at $6,000 \mathrm{~g}$ for $5 \mathrm{~min}$. A $10 \mu \mathrm{L}$ aliquot of each supernatant solution was loaded on a $10 \%$ polyacrylamide gel (Bio-Rad Laboratories, Hercules, CA, USA). At a constant voltage of $110 \mathrm{~V}$, the gels were run on a Bio-Rad Mini-Protean system (Bio-Rad) for $3 \mathrm{~h}$. The proteins were then stained with Coomassie Blue $\mathrm{R}-250$ for $30 \mathrm{~min}$ and destained for $24 \mathrm{~h}$ until the bands were clear. The gels were scanned (Tanon-2500; Bio-Tanon, Shanghai, China) at a resolution of $500 \mathrm{dpi}$.

\subsection{Physical Properties of the Fermented Chickpea Milk}

2.5.1. Texture Profile Analysis (TPA). The TPA of each sample was determined by CT3 (Brookfield Engineering Laboratories, Inc., USA). The intermediate layer of each sample was selected for texture analysis. The hardness (g), consistency (g.s), viscosity index (g.s), and cohesion (g) of the samples were measured with a cylindrical TA4/1000 probe under $1 \mathrm{~mm} / \mathrm{s}$ test speed, $0.5 \mathrm{~mm} / \mathrm{s}$ pretest speed, $1 \mathrm{~mm} / \mathrm{s}$ posttest speed, $30 \%$ compressed strain, and $5 \mathrm{~s}$ compression interval.

The color of each fermented sample for $24 \mathrm{~h}$ was determined with a Konica Minolta CR-400 spectrophotometer (Konica Minolta Holdings Inc., Japan). The fermented sample was filled in a glass cuvette, and the CIELAB tristimulus color values of lightness/darkness $\left(L^{*}\right)$, redness/greenness $\left(a^{*}\right)$, and yellowness/blueness $\left(b^{*}\right)$ were measured at $25^{\circ} \mathrm{C}$.

\subsection{Determination of Antioxidant Capacity}

2.6.1. DPPH Radical Scavenging Assay. The fermented samples were analyzed for the scavenging effect on DPPH radical as described by Soison et al. [20] with minor modification. Each sample $(1 \mathrm{~mL})$ of $0,3,6,9,12$, and $24 \mathrm{~h}$ was mixed with $3 \mathrm{~mL}$ of $0.2 \mathrm{mmol} / \mathrm{L} \mathrm{DPPH}$ ethanol solution. The absorbance of the reaction mixture was measured at $517 \mathrm{~nm}$ after reaction in darkness at room temperature for $30 \mathrm{~min}$. The blank control consisted of 95\% ethanol and DPPH ethanol solution. The DPPH free radical scavenging rate (\%) of each sample was calculated in accordance with the following equation:

$$
\text { DPPH scavenging rate }(\%)=\left[\frac{\left(\mathrm{A}_{0}-\mathrm{A}_{\mathrm{s}}\right)}{\mathrm{A}_{0}}\right] \times 100 \% \text {, }
$$

where $A_{0}$ is the absorbance of the blank and $A_{\mathrm{s}}$ is the absorbance of the samples.

2.6.2. Determination of Ferric Reducing Antioxidant Power (FRAP). The FRAP antioxidant capacity of fermented samples was determined in accordance with the method of
Oyaizu [21] and Marazza [22] with some modifications. An aliquot $(2.0 \mathrm{~mL})$ of the fermented sample was mixed with $2.0 \mathrm{~mL}$ of $\mathrm{pH} 6.6$ phosphate buffer $(0.2 \mathrm{M})$ and $2.0 \mathrm{~mL}$ of $1 \%$ potassium ferricyanide. The mixture was incubated at $50^{\circ} \mathrm{C}$ for $20 \mathrm{~min}$, and then $10 \%$ trichloroacetic acid $(2.0 \mathrm{~mL})$ was added. The mixture was centrifuged at $6,000 \mathrm{~g}$ at $4^{\circ} \mathrm{C}$ for $10 \mathrm{~min}$. The supernatant was mixed with $0.1 \%$ ferric chloride $(1.0 \mathrm{~mL})$ and deionized water $(5.0 \mathrm{~mL})$. The absorbance was measured at $700 \mathrm{~nm}$ after $10 \mathrm{~min}$.

2.6.3. ABTS Radical Scavenging Assay. ABTS radical scavenging activity was determined, as described by Raquel [23] with some modifications. $\mathrm{ABTS}^{+}(7 \mathrm{mmol} / \mathrm{L})$ and potassium persulfate $(140 \mathrm{mmol} / \mathrm{L})$ were prepared separately. Under the dark condition, $1.76 \mathrm{~mL}$ potassium persulfate solution and $100 \mathrm{~mL} \mathrm{ABTS}^{+}$were mixed evenly and reacted overnight. The prepared liquor with $95 \%$ ethanol was diluted. The absorbance at $734 \mathrm{~nm}$ is $0.700 \pm 0.02$. Subsequently, $1.0 \mathrm{~mL}$ of the sample solution was mixed with $3 \mathrm{~mL}$ of ABTS radical solution, and the absorbance was recorded at $734 \mathrm{~nm}$.

2.7. Statistical Analysis. Each experiment was conducted thrice, and results are presented as the mean values $(n=3) \pm$ standard deviation (SD). Differences among different groups were analyzed by using analysis of variance and Duncan's multiple range test. Differences were considered significant at $p<0.05$ level.

\section{Results and Discussion}

3.1. Polysaccharide Contents of Different Samples during Fermentation. As presented in Figure 1, the polysaccharide contents of samples in the four groups declined gradually from $0 \mathrm{~h}$ to $12 \mathrm{~h}$. This phenomenon was because the polysaccharide molecules were hydrolyzed by lactic acid bacteria to provide a carbon source for their proliferation during the fermentation process. Therefore, the polysaccharide content gradually decreased, which was consistent with Hong's report [24].

As shown in Figure 1, the chickpea yam fermented milk without hydrolyzed enzyme in the four samples had higher polysaccharide content than those of enzymatically fermented chickpea yam milk. This condition was due to the enzymatic hydrolysis of polysaccharide molecules, resulting in a decrease in its content. The content of polysaccharides in fermented milk with yam addition was high. This condition was because the total polysaccharide content was increased by polysaccharide contained in yam itself.

3.2. FTIR Analysis. The FTIR spectra of fermented samples at 0,12 , and $24 \mathrm{~h}$ are presented in Figure 2. Results showed that the bands at 1019 and $1153 \mathrm{~cm}^{-1}$ of four samples fermented for $0 \mathrm{~h}$ indicated the $\mathrm{O}-\mathrm{H}$ absorption peak and the $\mathrm{C}-\mathrm{O}$ bending vibration, which were the characteristic bands of polysaccharides. Similar results were obtained by Yan [25]. The absorption peak at $1641 \mathrm{~cm}^{-1}$ indicated the 


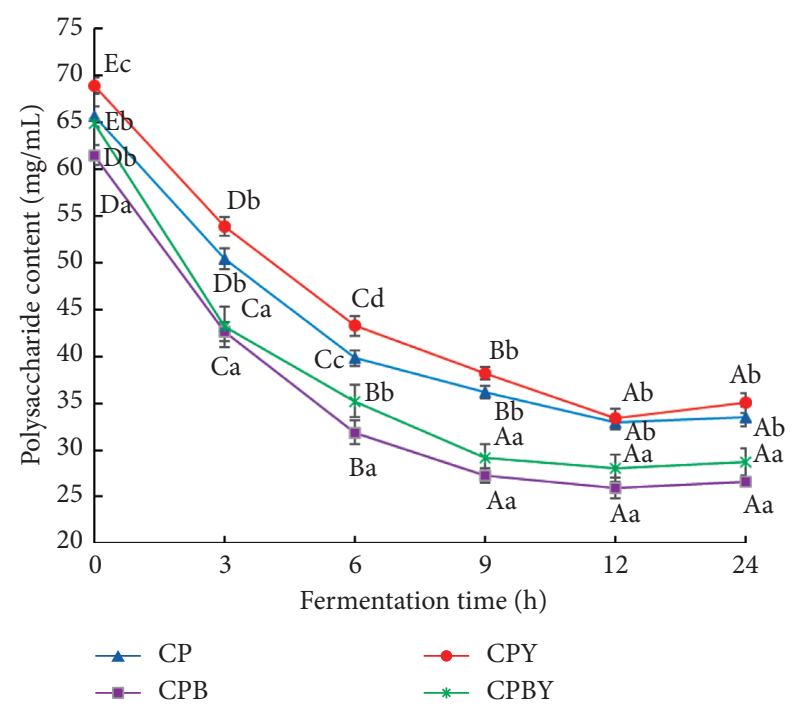

Figure 1: Polysaccharide contents of four samples at different fermentation times. All the values are expressed as mean $\pm S D$ $(n=3)$. Means with different uppercase letters indicate significant differences of the same sample at the different fermentation time $(p<0.05)$. Means with different lowercase letters indicate a significant difference of four group samples at the same fermentation time $(p<0.05)$. CP: chickpea fermentation milk; CPB: chickpea fermentation milk with enzyme hydrolysis; CPY: chickpea yam fermentation milk; CPBY: chickpea yam fermentation milk with enzyme hydrolysis.

stretching of carbonyl $(\mathrm{C}=\mathrm{O})$ [26]. The weak band at $2902 \mathrm{~cm}^{-1}$ was attributed to the stretching vibration of methylene $(-\mathrm{CH})$, and the hydroxyl group was identified by the broad band at $3423 \mathrm{~cm}^{-1}$.

Compared with the samples at $0 \mathrm{~h}$, the four samples fermented for $12 \mathrm{~h}$ had the band at $485 \mathrm{~cm}^{-1}$, indicating the deformation vibration of C-C-C. The band at 1019 and $1041 \mathrm{~cm}^{-1}$ indicated the stretching vibration of $\mathrm{C}-\mathrm{O}$. The former was the ether group $(\mathrm{C}-\mathrm{O}-\mathrm{C})$ of the pyran ring, whereas the latter was $\mathrm{C}-\mathrm{O}-\mathrm{H}$ [25]. The peaks near $1078 \mathrm{~cm}^{-1}$ were ascribed to the ether group, the peak at $1651 \mathrm{~cm}^{-1}$ was the carboxyl group, and the band at $2923 \mathrm{~cm}^{-1}$ indicated the stretching vibration of saturated $\mathrm{C}-\mathrm{H}$. The hydroxyl absorption peak was at $3427 \mathrm{~cm}^{-1}$, and the antioxidant activity of polysaccharides was connected with the number of hydroxyl groups [27].

Compared with the samples at $0 \mathrm{~h}$, the four samples fermented for $24 \mathrm{~h}$ contained the peaks at $436 \mathrm{~cm}$ the $\mathrm{c}^{-1}$, indicating the deformation vibration of $\mathrm{C}-\mathrm{C}-\mathrm{C}$. The band at $759 \mathrm{~cm}^{-1}$ was ascribed to degraded D-glucose of the polysaccharides in four samples during fermentation, which was consistent with Hong's results [24]. The two absorption peaks observed in the spectra at 929 and $1022 \mathrm{~cm}^{-1}$ were the $\mathrm{C}-\mathrm{O}$ stretching vibration, indicating a $\beta$-pyranose ring structure. The region around $1154-1079 \mathrm{~cm}^{-1}$ can be used to infer the position of the ether groups in polysaccharides [28]. The peak near $1660-1206 \mathrm{~cm}^{-1}$ was assigned to the carboxyl group, and the peak at $2924 \mathrm{~cm}^{-1}$ was ascribed to the alkyl group. The peak located at $3404 \mathrm{~cm}^{-1}$ was the $\mathrm{O}-\mathrm{H}$ stretching vibration in the associated state. However, all the four samples had characteristic bands of polysaccharides, which were $\beta$-pyranose ring structures.

As shown in Figure 2, the infrared spectrum characteristics of the four samples CP, CPB, CPY, and CPBY fermented at 0,12 , and $24 \mathrm{~h}$ were similar. However, the transmittance of some specific wavelength characteristic bands was different.

3.3. Effect of Fermentation on Protein Subunit Composition. SDS-PAGE (Figure 3) of four samples reflected the effect of fermentation treatment on the composition of chickpea milk protein subunits. $7 \mathrm{~S}$ protein and $11 \mathrm{~S}$ protein are the main components of chickpea storage proteins. The 7S protein contained three subunits: $\alpha, \alpha^{\prime}$, and $\beta$. The $11 \mathrm{~S}$ protein was divided into acidic subunit $A$ and basic subunit $B$. The 94.3 KDa subunit band of the CPBY sample at $0 \mathrm{~h}$ disappeared, and the four groups of samples at $0 \mathrm{~h}$ demonstrated an intensification of bands in the range of 20.1-14.3 KDa by comparing Figures 3(a) and 3(b) of the SDS-PAGE profiles of protein. The SDS-PAGE profiles of the $\mathrm{CPB}$ sample treated with papain at $0 \mathrm{~h}$ illustrated the lightening of $7 \mathrm{~S} \alpha^{\prime}$ band.

In accordance with Figure 3(b), the SDS-PAGE profiles of four samples fermented for $24 \mathrm{~h}$ showed a band disappearance in the range of $94.3 \mathrm{KDa}$ and the lightening of bands in the range of 44.3-94.3. The bands in the range of 29.0-44.3 KDa of the CPB sample fermented for $24 \mathrm{~h}$ lightened. The bands in the range of 44.3-94.3 KDa of the CP, CPY, and CPBY fermented for $24 \mathrm{~h}$ lightened, and more small-molecule protein peptides were generated. In particular, the SDS-PAGE profiles of four samples showed an intensification of bands in the range of 29.0-20.1 KDa. These proteins were identical to the polypeptide chains A and $B$ of the $11 S$ protein [29]. The extracellular enzymes produced by lactic acid bacteria fermentation had certain hydrolysis power. The result indicated that the $11 \mathrm{~S}$ protein of chickpea milk was less prone to hydrolysis than the $7 \mathrm{~S}$ protein.

3.4. Physical Characteristics of the Samples. The physical characteristics of fermented samples were the vital aspect influencing customers' assessment on the quality of fermented chickpea milk. As shown in Table 1, a difference was observed in terms of firmness among the four samples, revealing that $\mathrm{CP}>\mathrm{CPY}>\mathrm{CPB}>\mathrm{CPBY}$. Some previous reports found correlations between the structure of chickpea globulin and the gel structure, where chickpea globulin was relatively compact and had weak flexibility, thereby forming a hard and brittle gel structure [30]. Therefore, the firmness of the CP sample was the highest. The firmness of CPB and CPBY samples after enzymatic hydrolysis and yam milk addition decreased, and the consistency increased. In accordance with the viscosity index, the viscosity of the $\mathrm{CP}$ sample was low $(p<0.05)$, and no significant difference was found in the viscosity of CPB, CPY, and CPBY samples $(p>0.05)$. The cohesion of the four samples was not significantly different $(p>0.05)$. The addition of yam milk and protease promoted the proliferation of lactic acid bacteria in 


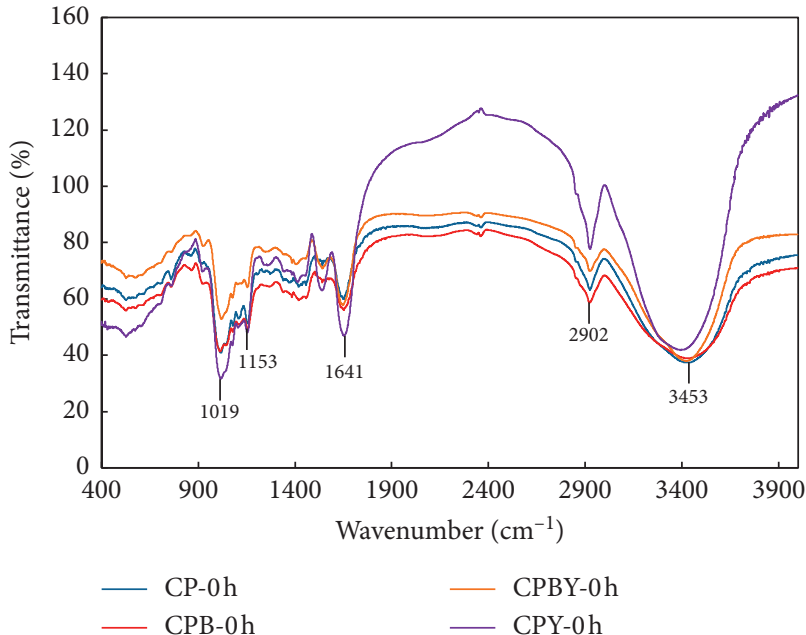

(a)

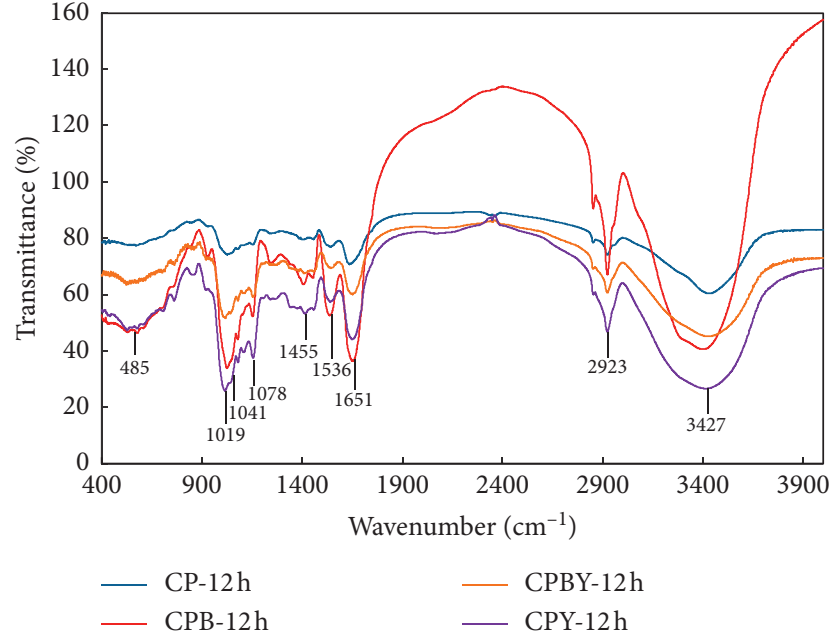

(b)

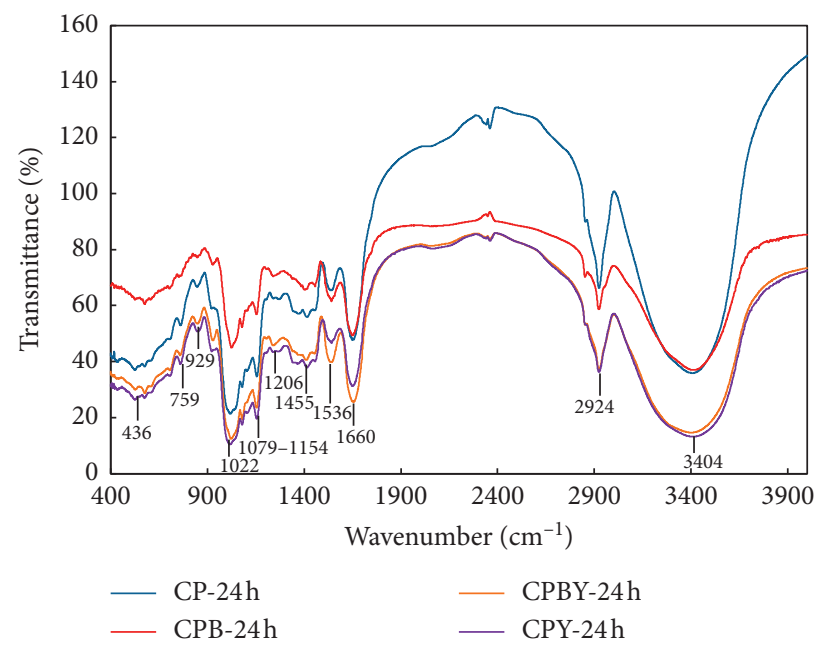

(c)

FIGURE 2: FTIR spectrum analysis of polysaccharides of four samples at $0 \mathrm{~h} \mathrm{(a),} 12 \mathrm{~h}$ (b), and $24 \mathrm{~h}(\mathrm{c})$. CP, chickpea fermentation milk; CPB, chickpea fermentation milk with enzyme hydrolysis; CPY, chickpea yam fermentation milk; CPBY, chickpea yam fermentation milk with enzyme hydrolysis.

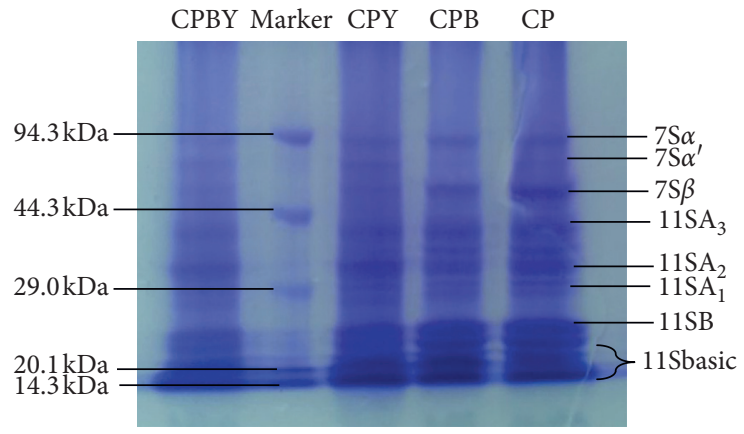

(a)

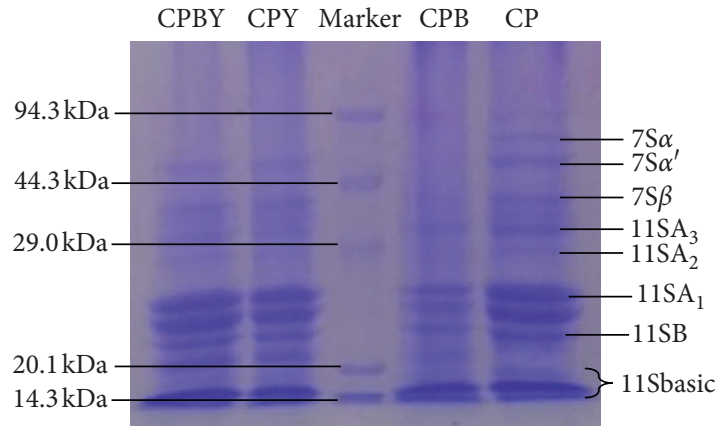

(b)

FIGURE 3: SDS-PAGE diagram of four samples at $0 \mathrm{~h}(\mathrm{a})$ and $24 \mathrm{~h}(\mathrm{~b}) . \mathrm{CP}$, chickpea fermentation milk; CPB, chickpea fermentation milk with enzyme hydrolysis; CPY, chickpea yam fermentation milk; CPBY, chickpea yam fermentation milk with enzyme hydrolysis. 
TABLE 1: The TPA of four samples of fermented milk.

\begin{tabular}{lcccc}
\hline Samples & Firmness (g) & Consistency (g.s) & Cohesion & Viscosity index (g.s) \\
\hline CP & $28.34 \pm 0.06^{\mathrm{c}}$ & $425.01 \pm 1.89^{\mathrm{a}}$ & $0.52 \pm 0.05^{\mathrm{a}}$ & $19.41 \pm 0.47^{\mathrm{a}}$ \\
$\mathrm{CPB}$ & $27.13 \pm 0.02^{\mathrm{b}}$ & $457.32 \pm 4.13^{\mathrm{b}}$ & $0.53 \pm 0.07^{\mathrm{a}}$ & $21.6 \pm 1.35^{\mathrm{b}}$ \\
CPY & $27.58 \pm 0.03^{\mathrm{b}}$ & $461.86 \pm 2.37^{\mathrm{b}}$ & $0.55 \pm 0.08^{\mathrm{a}}$ & $21.8 \pm 0.26^{\mathrm{b}}$ \\
CPBY & $26.67 \pm 0.01^{\mathrm{a}}$ & $488.49 \pm 3.52^{\mathrm{c}}$ & $0.56 \pm 0.03^{\mathrm{a}}$ & $22.35 \pm 0.71^{\mathrm{b}}$ \\
\hline
\end{tabular}

All the values are expressed as mean $\pm \mathrm{SD}(n=3)$. Different superscript lowercase letters in the same column indicate significant differences $(p<0.05)$. CP, chickpea fermentation milk; $\mathrm{CPB}$, chickpea fermentation milk with enzyme hydrolysis; CPY, chickpea yam fermentation milk; CPBY, chickpea yam fermentation milk with enzyme hydrolysis.

fermented chickpea milk to produce hydrolase for degrading polysaccharides in fermented milk. This condition affected its viscosity [7] and resulted in delicate and smooth fermented chickpea milk.

As an important visual indicator, color plays a key role in influencing consumers' impression on the quality of plantbased fermented milk products. The results in Table 2 revealed that some color variation trends of fermented chickpea milk samples can be concluded after fermentation for $24 \mathrm{~h}$. Among the four samples, the $L^{*}$ of CPY was the highest (86.90), and the $L^{*}$ of CP was the lowest (83.05) $(p<0.05)$. The $a^{*}$ values of CPB and CPBY samples with enzymatic hydrolysis decreased $\left(a^{*}\right.$ was -3.26 and -3.23 , respectively). This condition represented that the fermented chickpea milk seemed to be brighter and greener after enzymatic hydrolysis. Previous studies on soy yogurt with enzymatic hydrolysis reported similar results [31]. The $b^{*}$ value of the CPBY sample was the lowest (9.08). However, a small difference was observed in the CPY sample (9.12). A significant difference was observed for yellowness $\left(b^{*}\right)$ between the CPB and CPY samples $(p<0.05)$. On the whole, moderate enzymatic hydrolysis had no adverse effect on the color of the sample, and the $L^{*}$ of the sample with yam milk addition becomes bright. Hence, enzymatic hydrolysis and yam milk addition can be used for the processing of fermented chickpea milk.

\subsection{Analysis of Antioxidant Activity}

3.5.1. DPPH Radical Scavenging Rate Analysis. As a classic method for evaluating the free radical scavenging activity, the DPPH radical scavenging has been widely adopted [32]. As shown in Figure 4, in the fermentation progress, The DPPH radical scavenging rate of the four samples increased with the extension of fermentation time, and the increase in DPPH radical scavenging rates decreased after $12 \mathrm{~h}$. As shown in Figure 4, some differences in DPPH were observed after $24 \mathrm{~h}$ fermentation among the four samples. A significant increase $(p<0.05)$ in DPPH radical scavenging rates was observed in the CPBY sample with enzymatic hydrolysis and yam milk addition (reaching 73.6\%), followed by CPY. The CP sample had the lowest DPPH radical scavenging rate. The results of DPPH radical scavenging activity clearly revealed that enzymatic hydrolysis and yam milk addition facilitated to enhance the antioxidant activity of the CPBY sample. This condition was because the polyphenols and other active ingredients contained in yam were released during the fermentation process. This condition can be
TABLE 2: The color features of four samples of fermented milk.

\begin{tabular}{lccc}
\hline \multirow{2}{*}{ Samples } & \multicolumn{3}{c}{ Color characteristic value } \\
& $L^{*}$ & $a^{*}$ & $b^{*}$ \\
\hline CP & $83.05 \pm 0.08^{\mathrm{a}}$ & $-2.81 \pm 0.05^{\mathrm{a}}$ & $10.63 \pm 0.12^{\mathrm{b}}$ \\
CPB & $85.36 \pm 0.12^{\mathrm{b}}$ & $-3.26 \pm 0.18^{\mathrm{b}}$ & $10.27 \pm 0.07^{\mathrm{b}}$ \\
CPY & $86.90 \pm 0.26^{\mathrm{c}}$ & $-2.72 \pm 0.03^{\mathrm{a}}$ & $9.12 \pm 0.35^{\mathrm{a}}$ \\
CPBY & $86.52 \pm 0.53^{\mathrm{c}}$ & $-3.23 \pm 0.06^{\mathrm{b}}$ & $9.08 \pm 0.16^{\mathrm{a}}$ \\
\hline
\end{tabular}

All the values are expressed as mean \pm SD $(n=3)$. Different superscript lowercase letters in the same column indicate significant differences $(p<0.05)$. CP, chickpea fermentation milk; CPB, chickpea fermentation milk with enzyme hydrolysis; CPY, chickpea yam fermentation milk; CPBY, chickpea yam fermentation milk with enzyme hydrolysis.

helpful to increase the antioxidant capacity of chickpea milk. This finding was consistent with the study of Lee [33].

3.5.2. Analysis of ABTS Free Radical Scavenging Ability. As shown in Figure 5, the change trend of the ABTS radical scavenging rate was similar to that of the DPPH radical scavenging rate. Compared with the counterpart of samples at $0 \mathrm{~h}$, the ABTS radical scavenging rates of all samples gradually increased during $24 \mathrm{~h}$ fermentation and reached the highest at $12 \mathrm{~h}$. Among the four samples, the ABTS radical scavenging rate of the $\mathrm{CPB}$ sample with enzymatic hydrolysis was higher than that of the $\mathrm{CP}$ sample without enzymolysis. This finding indicated that small-molecule peptides may be released in chickpea milk during proteolysis. This condition can be helpful to enhance its antioxidant capability. The CPBY sample with yam milk addition had the highest ABTS radical scavenging rate after $12 \mathrm{~h}$ fermentation, reaching $73.89 \%(p<0.05)$. It can be speculated that the polysaccharide of yam and protein of chickpea emerged as the polysaccharide-protein conjugate, which contained crevasses, and hydrophobic cavities increased the antioxidant activities [34].

3.5.3. FRAP Antioxidant Capacity Analysis. As shown in Figure 6, a significant increase in FRAP antioxidant capacity of four samples was observed in the chickpea milk during $24 \mathrm{~h}$ fermentation $(p<0.05)$. However, the FRAP antioxidant capacity increased slightly after fermentation for $12 \mathrm{~h}$. The order of the FRAP antioxidant capacity of four samples was $\mathrm{CPBY}>\mathrm{CPY}>\mathrm{CPB}>\mathrm{CP}$. The CPBY sample with enzymatic hydrolysis had the highest FRAP antioxidant capacity after $24 \mathrm{~h}$ fermentation, reaching $398.86 \mathrm{mmol}$ Trolox/mL. 


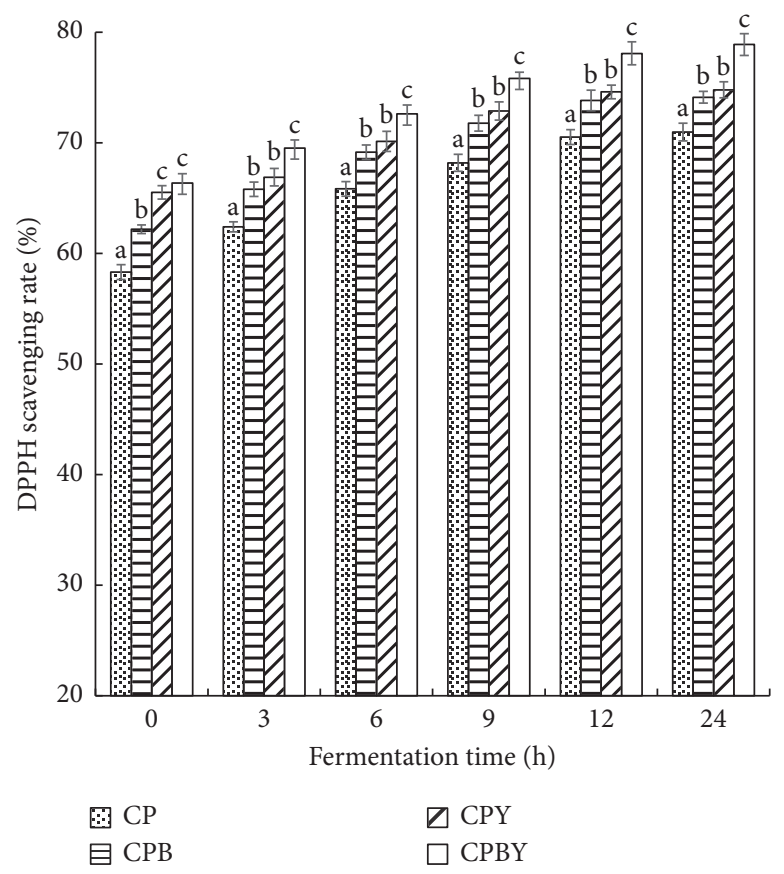

FIGURE 4: DPPH free radical scavenging rate of four samples at different fermentation times. All the values are expressed as mean \pm SD $(n=3)$. Means with different lowercase letters indicate a significant difference of four group samples at the same fermentation time $(p<0.05)$. CP, chickpea fermentation milk; CPB, chickpea fermentation milk with enzyme hydrolysis; CPY, chickpea yam fermentation milk; CPBY, chickpea yam fermentation milk with enzyme hydrolysis.

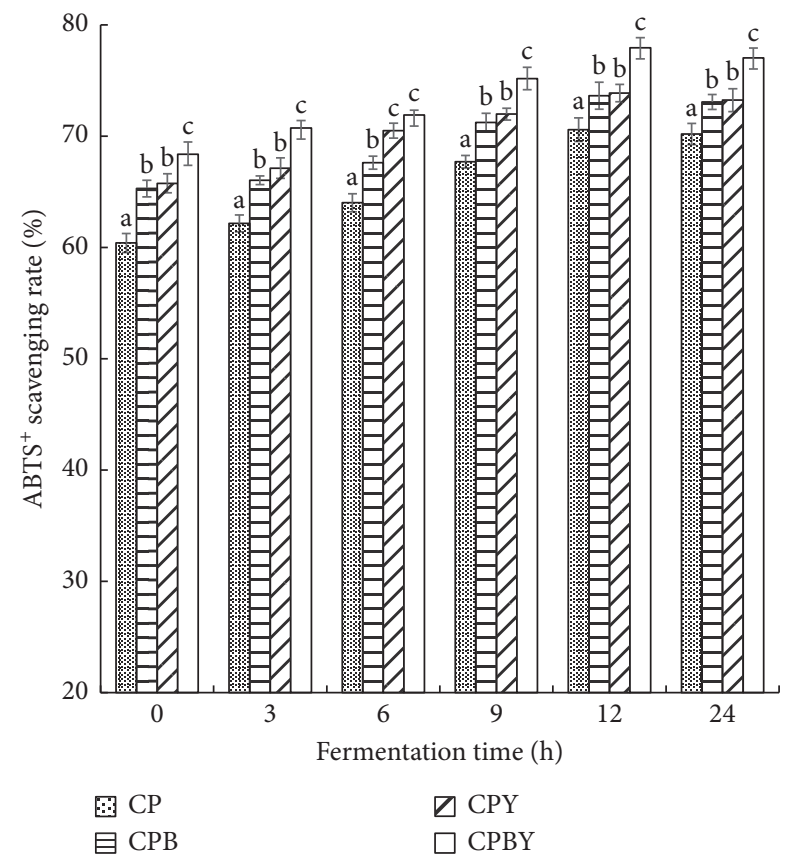

FIGURE 5: ABTS + free radical scavenging rate of four samples at different fermentation times. All the values are expressed as mean \pm SD $(n=3)$. Means with different lowercase letters indicate a significant difference of four group samples at the same fermentation time $(p<0.05)$. CP, chickpea fermentation milk; CPB, chickpea fermentation milk with enzyme hydrolysis; CPY, chickpea yam fermentation milk; CPBY, chickpea yam fermentation milk with enzyme hydrolysis.

We hypothesized that the enhancement of the antioxidant capacity of chickpea fermented milk might be related to the change in bioactive ingredients, such as polysaccharides, or the conversion of bioactive compounds, such as protein, during the fermentation process. As mentioned above, the changes in polypeptide content caused by protease hydrolysis during fermentation lead to the release of antioxidant materials. The research of Sung-Mee Lim et al. [35] showed 


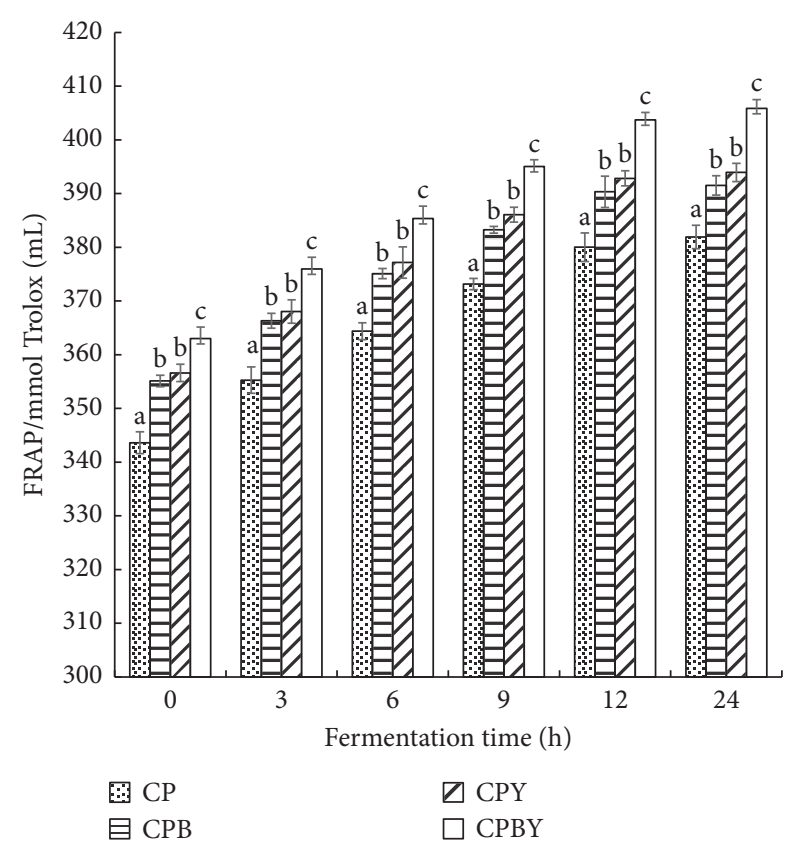

FIgURE 6: FRAP antioxidant capacity of four samples at different fermentation times. All the values are expressed as mean \pm SD $(n=3)$. Means with different lowercase letters indicate a significant difference of four group samples at the same fermentation time $(p<0.05)$. CP, chickpea fermentation milk; CPB, chickpea fermentation milk with enzyme hydrolysis; CPY, chickpea yam fermentation milk; CPBY, chickpea yam fermentation milk with enzyme hydrolysis.

that the proteins and peptides in chickpea milk are positively correlated with free radical scavenging activity. Studies showed that the biologically active peptides released through the fermentation process can increase the antioxidant activity [20]. In this study, the enhancement of antioxidant capacity was related to the changes in biologically active compounds, such as proteins. Moreover, the antioxidant capacity was highly correlated with proteolytic activity. External factors such as enzymatic hydrolysis can hydrolyze proteins and produce some hydrophobic amino acids. The antioxidant capacity depended on peptides, amino acids, and other bioactive substances in chickpea milk, such as polysaccharides and polyphenols. This finding implied that lactic acid bacteria fermentation had obvious effects on the antioxidant bioactivity of chickpea milk. This condition was probably attributed to the alteration of its physicochemical characteristics.

\section{Conclusion}

In this study, four groups of chickpea milk were prepared through fermentation with lactic acid bacteria for quality and function improvement. The results indicated that the polysaccharide content of four samples declined during the $24 \mathrm{~h}$ fermentation process. The infrared spectrums were similar, but the transmittances of some characteristic bands were different. The SDS-PAGE profiles of four samples fermented for $24 \mathrm{~h}$ showed a band disappearance in the range of $94.3 \mathrm{KDa}$ and generation of more small-molecule peptides, revealing the protein degradation during fermentation. The moderate enzymatic hydrolysis had no adverse effect on the texture and color of the samples. A significant increase in DPPH, ABTS radical scavenging rate, and FRAP value was observed in the $0-12 \mathrm{~h}$ fermentation, especially the CPBY sample, reaching $73.60 \%, 73.89 \%$, and $398.86 \mathrm{mmol}$ Trolox/mL, respectively. Accordingly, lactic acid bacteria fermentation can be developed to improve the physicochemical properties of chickpea milk and enhance its antioxidant activity.

\section{Data Availability}

The data used to support the findings of this study are available from the corresponding author upon request.

\section{Conflicts of Interest}

The authors declare that have no conflicts of interest.

\section{Acknowledgments}

This work was supported by Henan Provincial Key Scientific and Technological Research Projects of China (212102110343). The authors thank Baoying Wang for supporting FTIR determination and Zhen Zhang for performing SDS-PAGE.

\section{References}

[1] S. Sethi, S. K. Tyagi, and R. K. Anurag, "Plant-based milk alternatives an emerging segment of functional beverages: a review," Journal of Food Science and Technology, vol. 53, no. 9, pp. 3408-3423, 2016.

[2] C. Cortés, M. J. Esteve, A. Frıgola, and F. Torregrosa, "Quality characteristics of horchata (a Spanish vegetable beverage) treated with pulsed electric fields during shelf-life," Food Chemistry, vol. 91, no. 2, pp. 319-325, 2015.

[3] H. Kim, H. Kim, J. Bang, Y. Kim, L. R. Beuchat, and J.-H. Ryu, "Reduction of Bacillus cereus spores in sikhye, a traditional Korean rice beverage, by modified tyndallization processes with and without carbon dioxide injection," Letters in Applied Microbiology, vol. 55, no. 3, pp. 218-223, 2012.

[4] J. W. Hou, R. C. Yu, and C. C. Chou, "During fermentation with Bifidobacterial," Changes in Some Components of Soymilk, Food Research International, vol. 33, no. 5, pp. 393-397, 2000.

[5] S. Sanjukta and A. K. Rai, "Production of bioactive peptides during soybean fermentation and their potential health benefits," Trends in Food Science \& Technology, vol. 50, no. 4, pp. 1-10, 2016.

[6] R. V. Usha and B. V. Pradeep, "Antioxidant properties of soy milk fermented with Lactobacillus paracasei KUMBB005," International Journal of Pharmaceutical Sciences Review and Research, vol. 30, no. 01, pp. 39-42, 2015.

[7] J. Gou, D. A. Hoang, T. Salmon et al., "Effect of grape juice press fractioning on polysaccharide and oligosaccharide compositions of Pinot meunier and Chardonnay Champagne base wines," Food Chemistry, vol. 232, pp. 49-59, 2017.

[8] K.-I. Chen, M.-H. Erh, N.-W. Su, W.-H. Liu, C.-C. Chou, and K.-C. Cheng, "Soyfoods and soybean products: from 
traditional use to modern applications," Applied Microbiology and Biotechnology, vol. 96, no. 1, pp. 9-22, 2012.

[9] Y.-Y. Zhu, K. Thakur, J.-Y. Feng et al., "B-vitamin enriched fermented soymilk: a novel strategy for soy-based functional foods development," Trends in Food Science \& Technology, vol. 105, pp. 43-55, 2020.

[10] S. Lev-Yadun, A. Gopher, and S. Abbo, "The cradle of agriculture," Science, vol. 288, pp. 1062-1063, 2000.

[11] R. N. Chibbar, P. Ambigaipalan, and R. Hoover, "REVIEW: molecular diversity in pulse seed starch and complex carbohydrates and its role in human nutrition and health," Cereal Chemistry, vol. 87, no. 4, pp. 342-352, 2010.

[12] J. A. Wood and M. A. Grusak, "Nutritional value of chickpea," in Chickpea Breeding and Management, S. S. Yadav, R. Redden, W. Chen, and B. Sharma, Eds., pp. 101-142, CAB International, Wallingford, UK, 2007.

[13] A. K. Jukanti, P. M. Gaur, C. L. L. Gowda, and R. N. Chibbar, "Nutritional quality and health benefits of chickpea (Cicer arietinumL.): a review," British Journal of Nutrition, vol. 108, no. S1, pp. S11-S26, 2012.

[14] S. Wang, V. Chelikani, and L. Serventi, "Evaluation of chickpea as alternative to soy in plant-based beverages, fresh and fermented," $L w t$, vol. 97, no. 07, pp. 570-572, 2018.

[15] J. R. Jeon, J. S. Lee, C. H. Lee, J. Y. Kim, S. D. Kim, and D. H. Nam, "Effect of ethanol extract of dried Chinese yam (Dioscorea batatas) flour containing dioscin on gastrointestinal function in rat model," Archives of Pharmacal Research, vol. 29, no. 5, pp. 348-353, 2006.

[16] R. Luana and E. Rodrigues de Alencar, "Development of novel plant-based milk based on chickpea and coconut," LWT-food Science and Technology, vol. 128, pp. 96-106, 2020.

[17] J. C. De Man, M. Rogosa, and M. E. Sharpe, "A medium for the cultivation of lactobacilli," Journal of Applied Bacteriology, vol. 23, no. 1, pp. 130-135, 1960.

[18] W. Yang, Y. Wang, X. Li, and P. Yu, "Purification and structural characterization of Chinese yam polysaccharide and its activities," Carbohydrate Polymers, vol. 117, no. 6, pp. 1021-1027, 2015.

[19] P. Meinlschmidt, E. Ueberham, J. Lehmann, U. SchweiggertWeisz, and P. Eisner, "Immunoreactivity, sensory and physicochemical properties of fermented soy protein isolate," Food Chemistry, vol. 205, pp. 229-238, 2016.

[20] S. Bisri, J. Kamolwan, J. Anuvat et al., "Physico-functional and antioxidant properties of purple-flesh sweet potato flours as affected by extrusion and drum-drying treatments," International Journal of Food Science and Technology, vol. 49, pp. 2067-2075, 2014.

[21] Z. C. olod, "Trifolium species-derived substances and extracts-biological activity and prospects for medicinal applications," Journal of Ethnopharmacology, vol. 143, pp. 14-23, 2012.

[22] J. A. Marazza, M. A. Nazareno, G. S. de Giori, and M. S. Garro, "Enhancement of the antioxidant capacity of soymilk by fermentation with Lactobacillus rhamnosus," Journal of Functional Foods, vol. 4, no. 3, pp. 594-601, 2012.

[23] R. Lucas-González, M. Viuda-Martos, J. A. Pérez Álvarez, J. Fernández-López, and J. Fernández-López, "Changes in bioaccessibility, polyphenol profile and antioxidant potential of flours obtained from persimmon fruit (Diospyros kaki) coproducts during in vitro gastrointestinal digestion," Food Chemistry, vol. 256, no. 8, pp. 252-258, 2018.

[24] Y. R. Hong, Research on the Physicochemical Property and Biological Activity of Polysaccharides from Longan Pulp
Fermentation by Lactic Acid Bacteria, South China Normal University, Guangzhou, China, 2018.

[25] Y. Yan, X. Li, M. Wan et al., "Effect of extraction methods on property and bioactivity of water-soluble polysaccharides from Amomum villosum," Carbohydrate Polymers, vol. 117, pp. 632-635, 2015.

[26] X. Guo, Z. Wang, F. Pi, R. Pan, Z. Zhao, and S. Yu, "Sequential extraction and physicochemical characterization of polysaccharides from chicory (Cichorium intybus) root pulp," Food Hydrocolloids, vol. 77, pp. 277-285, 2018.

[27] Y. Yuan, C. Li, Q. Zheng et al., "Effect of simulated gastrointestinal digestion on the antioxidant activity, in vitro molecular weight and microstructure of polysaccharides from a tropical sea cucumber (Holothuria leucospilota)," Food Hydrocolloids, vol. 89, no. 4, pp. 735-741, 2018.

[28] H. Li, X. Wang, Q. Xiong, Y. Yu, and L. Peng, "Sulfated modification, characterization, and potential bioactivities of polysaccharide from the fruiting bodies of Russula virescens," International Journal of Biological Macromolecules, vol. 154, pp. 1438-1447, 2020.

[29] F. Vairinhos and D. R. Murray, "Changes in polypeptide composition during seed development in chickpea, cicer arietinum L," Zeitschrift für Pflanzenphysiologie, vol. 106, no. 5, pp. 447-452, 1982

[30] T. Zhang, "Preparation and functional properties of chickpea isolates," PHD Dissertation, Jiangnan University, Wuxi, China, 2005.

[31] Q. Yu, Study on the Effect of Enzymatic Action on the Quality of Soybean Yogurt, Master Dissertation, South China University of Technology, Guangzhou, China, 2015.

[32] M. K. Patel, B. Tanna, A. Mishra, and B. Jha, "Physicochemical characterization, antioxidant and anti-proliferative activities of a polysaccharide extracted from psyllium (P. ovata) leaves," International Journal of Biological Macromolecules, vol. 118, pp. 976-987, 2018.

[33] J.-G. Lee, "Antioxidant activities and monacolin K production on solid-state fermentation of diverse yam by Aspergillus species strain," The Korean Journal of Microbiology, vol. 50, no. 1, pp. 53-59, 2014.

[34] A.-L. Lee, Y.-P. Yu, J.-F. Hsieh, M.-I. Kuo, Y.-S. Ma, and C.-P. Lu, "Effect of germination on composition profiling and antioxidant activity of the polysaccharide-protein conjugate in black soybean [Glycine max (L.) Merr.]," International Journal of Biological Macromolecules, vol. 113, pp. 601-606, 2018.

[35] M. L. Sung, "Microbiological, physicochemical and antioxidant properties of plain yogurt and soy yogurt," Korean Journal of Microbiology, vol. 49, no. 4, pp. 403-414, 2013. 